\title{
Pelatihan Pemanfaatan Internet dalam Upaya Peningkatan Daya Saing Bisnis
}

\author{
Annas Setiawan Prabowo \\ Politeknik Negeri Cilacap
}

\author{
Riyadi Purwanto \\ Politeknik Negeri Cilacap
}

\author{
Lutfi Syafirullah \\ Politeknik Negeri Cilacap
}

Abdul Rohman Supriyono
Politeknik Negeri Cilacap

\section{Devi Taufiq Nurrohman}

Politeknik Negeri Cilacap

\begin{abstract}
Small and Medium Enterprises (UKM) have a large role in national economic development. In Indonesia, the majority of UKM are dominated by people with low education so that in the marketing process they still use conventional methods. This dedication activity conducted training on the use of the internet to improve the competitiveness of UKM in the Cilacap district. The material presented starts from creating a personal website for online marketing, making product descriptions, making videos and introducing SEO for optimization. The output of this training is in the form of an online sales website owned by each participant. The use of personal websites is expected to build the trust of prospective buyers and products from UKM are more accessible to the public from the use of the Google keyword planner.
\end{abstract}

Keywords: Small and Medium Enterprises; Online Marketing; SEO; Google Keyword Planner

\section{Abstrak}

Usaha kecil menengah (UKM) memiliki peran yang besar dalam pembangunan ekonomi nasional. Di Indonesia, pelaku UKM mayoritas didonimasi oleh masyarakat berpendidikan rendah sehingga dalam proses pemasarannya masih menggunakan cara konvensional. Kegiatan pengabdian ini melakukan pelatihan pemanfaatan internet untuk meningkatkan daya saing bisnis UKM di kabupaten Cilacap. Materi yang disampaikan mulai dari membuat website pribadi untuk penjualan online, membuat deskripsi produk, membuat video dan pengenalan SEO untuk optimasi. Luaran dari pelatihan ini berupa website penjualan online yang dimiliki oleh masing - masing peserta. Harapannya dengan adanya website pribadi kepercayaan calon pembeli mulai terbangun dan produk dari UKM lebih banyak diakses oleh masyarakat dari pemanfaatan Google keyword planner.

Kata kunci: Usaha Kecil Menengah (UKM); Penjualan Online; SEO ; Google Keyword Planner

\section{Pendahuluan}

Pertumbuhan ekonomi merupakan salah satu indikator dalam menentukan keberhasilan suatu negara. Beberapa indikator yang menunjukkan adanya pertumbuhan ekonomi diantaranya adalah bertambahnya produksi barang industri, berkembangnya infrastruktur, bertambahnya sekolah, bertambahnya barang modal dan bertambahnya sektor jasa (LAILY, 2016). Usaha kecil dan menengah (UKM) adalah salah satu bidang yang memberikan kontribusi yang signifikan dalam memacu pertumbuhan ekonomi di Indonesia (Jauhari, 2014). UKM yang selama ini telah berkembang telah terbukti mampu memunculkan potensi lokal daerah dan mengurangi angka pengangguran terutama bagi mereka yang berpendidikan rendah. Mengingat sangat pentingnya UKM, pemerintah telah menetapkan UU No.20 tahun 2008 yang berisi tentang usaha kecil dan menengah yang bertujuan untuk membangun perekonomian nasional yang berdasarkan pada demokrasi ekonomi yang berkeadilan sosial. 
Pemasaran merupakan ujung tombak dan menjadi penentu dalam keberlangsungan sebuah usaha termasuk UKM. Sebagus apapun produk yang dihasilkan oleh sebuah UKM namun jika tidak dibarengi dengan pemasaran yang baik maka akan mengancam keberlangsungan usaha pada UKM tersebut. Bidang inilah yang selama ini menjadi problematika utama yang ada di UKM. Karena pelaku UKM yang mayoritas didominasi oleh masyarakat berpendidikan rendah maka secara otomatis penguasaan teknologipun rendah (Sulistyo, 2010).

Pemanfaatan teknologi untuk memasarkan produk yang dikenal dengan pemasaran online (Online marketing) menjadi hal yang wajib dan dinilai efektif. Pengalaman terdahulu pernah dialami oleh perusahaan besar seperti perusahaan kodak. Karena strategi bisnisnya yang tidak menggunakan pemasaran online perusahaan ini akhirnya gulung tikar (Wahyudi \& Riyanto, n.d.). Oleh karena itu mengingat perkembangan teknologi yang begitu massif, pemanfaatan teknologi bagi pelaku UKM menjadi hal yang harus dilakukan.

Proses jual beli secara online yang terjadi sekarang ini melibatkan penjual dan pembeli yang mana tidak bertemu/bertatap muka secara langsung (Teguh, 2012). Oleh karena itu bagi pelaku UKM yang baru memasarkan barangnya secara online yang pertama harus dilakukan adalah membangun kepercayaan calon pembeli. Harapannya setelah kepercayaan tersebut terbangun, proses jual beli akan menjadi lebih mudah dan intens.

Berdasarkan data dari social research dan monitoring sociab, Kadin, Kemkominfo, Accenture tahun 2015, dari total pengguna internet di Indonesia sebanyak 77\% menggunakan internet untuk mencari produk dan belanja online (Harahap, 2018). Sebaliknya jumlah pemilik toko online terus meningkat tajam sehingga persaingan tidak bisa dihindarkan. Oleh karena itu jika tidak dibarengi dengan cara dan strategi yang tepat, penggunaan internet untuk pemasaran online menjadi tidak optimal.

Search Engine Optimization (SEO) merupakan salah satu cara yang tepat untuk untuk mendatangkan pengunjung di website seseorang supaya lebih banyak (Saefullah, Himawan, \& Arisantoso, 2015). Dengan memanfaatkan search engine yang dimiliki SEO akan berpengaruh pada pencarian produk yang dipilih calon pembeli. Selanjutnya fitur Google keyword planner juga dapat dimanfaatkan dalam menentukan kata kunci yang paling dicari oleh pengguna mesin pencari Google. Harapannya dengan menggunakan kata kunci yang tepat ini akan membantu dalam mencari berbagai peluang yang bisa dimanfaatkan untuk mendatangkan pelanggan.

Kegiatan pengabdian ini bertujuan untuk meningkatkan daya saing bisnis di UKM yang ada di kabupaten Cilacap dengan memberikan pelatihan dalam pemanfaatan internet. Mitra pengabdian dalam kegiatan ini adalah BSM Subur. Salah satu UKM di kabupaten Cilacap yang bergerak dibidang lingkungan, ekonomi, dan sosial. UKM ini menjual produk dan jasa. Adapun produk yang dihasilkan dari UKM ini adalah pupuk kompos, media tanam, gadged penanganan sampah, bibit sayur, dan sayur organik. Sedangkan jasa yang dihasilkan diantaranya adalah pelatihan, edukasi, demo, mentoring, penanganan sampah organik serta kerja sosial. Dengan memanfaatkan jejaring UKM yang dimiliki oleh BSM Subur, tim pengabdian Politeknik Negeri Cilacap mengundang UKM untuk ikut dan berpartisipasi dalam kegiatan pelatihan ini.

\section{Metode Pelaksanaan} berikut:

Kegiatan dapat dilaksanakan setelah sebelumnya melalui beberapa tahapan sebagai

1. Koordinasi dengan BSM Subur sebagai mitra pengabdian.

2. Koordinasi dengan beberapa UKM dari data UKM yang diperoleh dari BSM Subur

3. Pelatihan pemanfaatan internet

Kegiatan pelatihan dilaksanakan dengan tatap muka secara langsung dengan peserta pelatihan dan dilaksanakan di BSM Subur yang beralamat di Jalan Melon RT. 01 RW.08 Tambakreja, Cilacap. Topik yang disampaikan dalam kegiatan pelatihan disusun mengacu pada tujuan 
pelatihan yaitu pemanfaatan internet untuk meningkatkan daya saing bisnis. Luaran dalam kegiatan pelatihan ini ada 2 yaitu :

a. Setiap peserta dapat membuat website pribadi

b. Setiap peserta dapat membuat deskripsi produk UKM dengan memanfaatkan SEO dan Google Keyword Planner.

Materi yang diberikan dalam kegiatan pelatihan adalah sebagai berikut :

Tabel 1. Materi Pelatihan Pemanfaatan Internet

\begin{tabular}{cll}
\hline No & Materi ke- & \multicolumn{1}{c}{ Materi yang disampaikan } \\
\hline 1 & Satu & Pembuatan Email \\
2 & Dua & Membuat blog untuk berjualan \\
3 & Tiga & Membuat deskripsi produk \\
4 & Empat & Pengenalan Search Engine Optimalization (SEO) \\
5 & Lima & Riset kata kunci menggunakan Google Keyword Planner \\
6 & Enam & Membuat video dan melakukan editing untuk deskripsi produk \\
\hline
\end{tabular}

\section{Hasil dan Pembahasan}

\section{a. Pelaksanaan Kegiatan}

Pelatihan pemanfaatan internet dilaksanakan selama 2 hari yaitu pada tanggal 30 Agustus 2019 dan 2 September 2019. Kegiatan dilaksanakan di BSM Subur dan dihadiri oleh 40 orang yang berasal dari UKM yang ada di Cilacap. Produk yang dijual oleh pelaku UKM bermacam-macam mulai dari produk olahan makanan, percetakan, produk pada elemen kendaraan dan produk pupuk untuk pertanian. Disela- sela kegiatan juga dilaksanakan pengenalan produk dari masing-masing UKM untuk mengenalkan produk supaya lebih dikenal oleh peserta pelatihan.

Peserta yang hadir pelatihan memiliki usia yang beragam mulai dari sekitar 20 sampai 50 tahun. Oleh karena itu dalam pelaksanaannya materi yang disampaikan diawali dengan materi yang sangat dasar berupa pembuatan email sampai dengan proses pembuatan video dan proses editingnya. Pelatihan ini menitikberatkan pada penggunaan SEO (search engine optimization) dan pemanfaatan Google keyword planner. Sebelum masuk ke materi tersebut terlebih dahulu diawali dengan pelatihan pembuatan deskripsi produk yang menjelaskan apa saja yang wajib ditulis dalam website ketika melakukan penjualan online. Deskripsi produk yang telah dibuat kemudian ditelusuri dan diteliti kata kunci terbaiknya menggunakan Google keyword planner. Adapun penggunaan SEO lebih menekankan pada optimasi pada On Page dengan jalan modifikasi faktor-faktor tertentu dari bagian dalam suatu website seperti menentukan tittle, tag, content yang relevan dengan tittle dan lain-lain. Gambar 1 menunjukkan beberapa dokumentasi kegiatan pelatihan pemanfaatan internet.

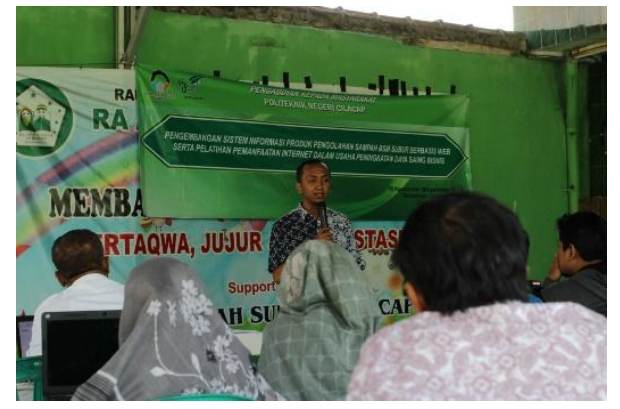

(a)

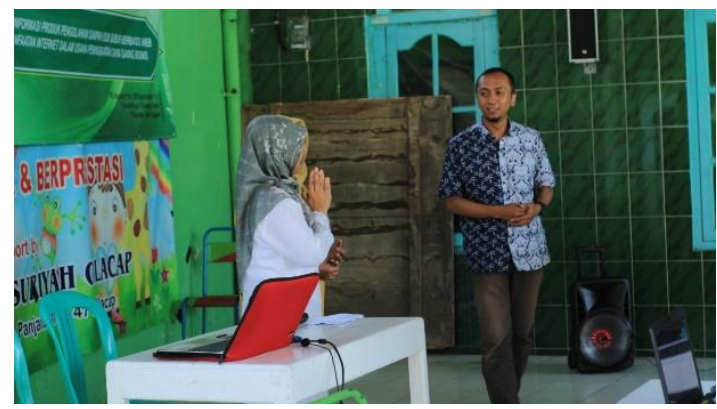

(b) 


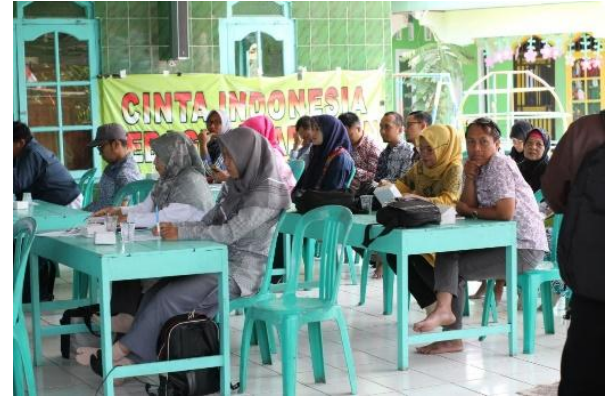

(c)

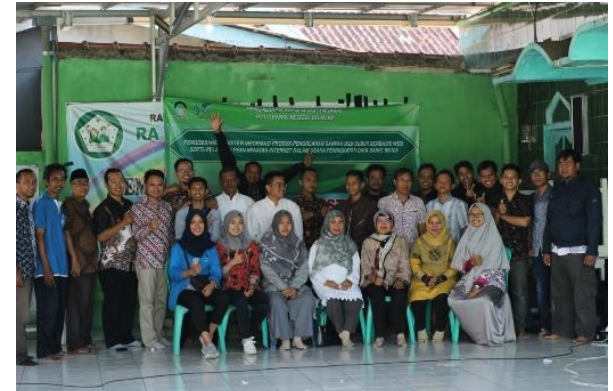

(d)

Gambar 1. (a) Dokumentasi ketika penyampaian materi, (b) Dokumentasi ketika sesi pengenalan produk pada masing-masing UKM, (c) Peserta pada saat materi, dan (d) Dokumentasi setelah kegiatan selesai

\section{b. Evaluasi Kegiatan}

Tujuan dari kegiatan pengabdian ini adalah memberikan keterampilan kepada perwakilan peserta UKM yang ada di kabupaten Cilacap dalam menjual/memasarkan produknya secara online dengan memanfaatkan media internet. Keterampilan yang dimaksud tersebut berupa keterampilan dalam membuat website online untuk berjualan dan keterampilan dalam membuat deskripsi produk barang yang dijual oleh masing-masing UKM. Untuk mengetahui apakah keterampilan tersebut telah tercapai atau belum maka dilakukan proses evaluasi.

Evaluasi dalam kegiatan pelatihan ini terbagi menjadi dua, Yang pertama adalah evaluasi dari segi konten pelatihan dan yang kedua adalah evaluasi teknis dalam pelaksanaan kegiatan. Dalam evaluasi konten pelatihan dilakukan dengan memberikan pretest dan postest kepada seluruh peserta yang hadir. Materi yang ditanyakan dalam pretest dan postest mencakup hal mendasar dan istilah-istilah yang wajib diketahui bagi seseorang yang berjualan secara online. Nilai pretest dan postest tersebut dapat dijadikan patokan seberapa besar materi yang diberikan telah tersampaikan dan diterima peserta. Gambar 2a menunjukkan salah satu contoh isian peserta pada saat pretest. Selain itu setelah pelatihan, seluruh peserta yang hadir diberikan tugas untuk membuat deskripsi produk barangnya secara mandiri dan selanjutnya menguploadnya ke website masing - masing. Dari deskripsi yang telah dibuat oleh peserta selanjutnya dibahas bersama-sama kelebihan dan kekurangannya. Gambar 2b menunjukkan salah satu website dan deskripsi produk yang dibuat oleh salah satu peserta pelatihan.

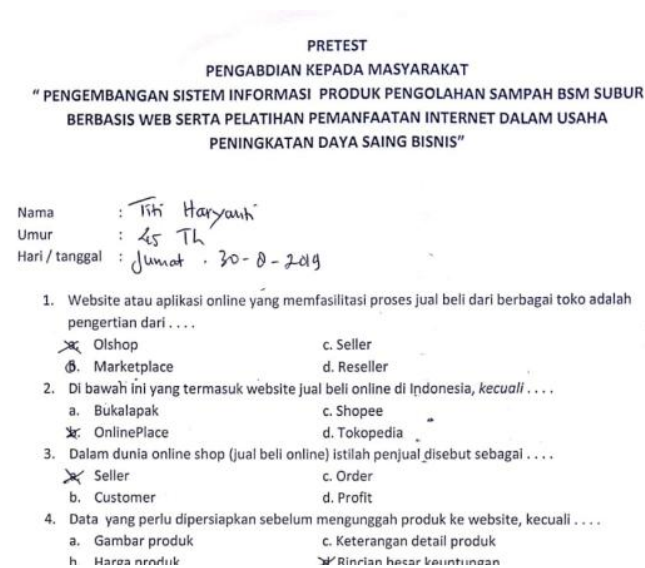

(a)

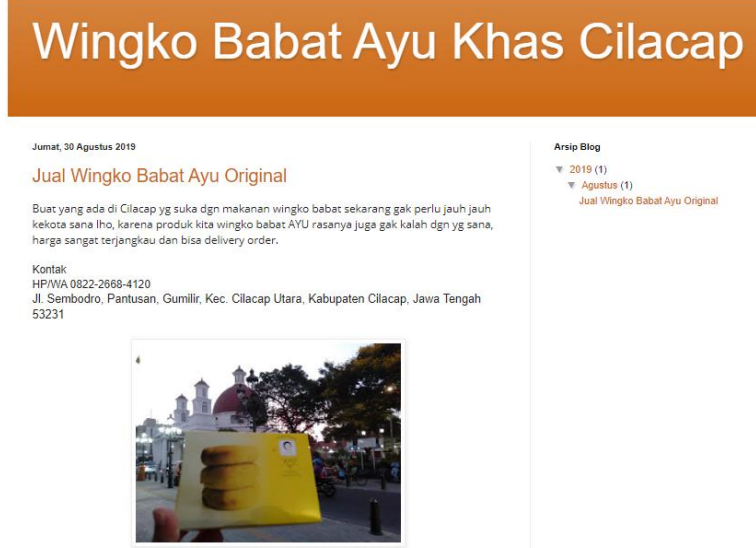

(b)

Gambar 2. (a) Salah satu isian peserta pada saat pretest dan (b) Salah satu website dan deskripsi produk yang dibuat peserta 
Evaluasi yang kedua adalah evaluasi dalam pelaksanaan kegiatan. Kegiatan pelatihan pemanfaatan internet untuk meningkatkan daya saing bisnis yang telah dilakukan mendapatkan respon yang sangat baik dari peserta pelatihan. Hal tersebut dapat dilihat pada saat penyampaian materi ketika pelatihan. Terdapat materi tambahan yang mana merupakan permintaan langsung dari peserta. Namun didalam pelaksanaannya kegiatan ini memiliki kendala diantaranya adalah karena faktor internet. Koneksi yang terputus-putus pada saat penyampaian materi membuat kegiatan praktek menjadi terhambat. Selain itu karena penguasaan komputer peserta pelatihan yang masih rendah mengakibatkan materi yang telah disusun sebelumnya harus diselesaikan dalam waktu yang lebih lama lagi.

\section{Kesimpulan}

Berdasarkan kegiatan pengabdian kepada masyarakat yang dilakukan di BSM Subur Cilacap dapat disimpulkan sebagai berikut :

a. Pemanfaatan internet sebagai media untuk menjual produk secara online di UKM yang hadir selama kegiatan pengabdian masih kurang disebabkan karena keterampilan peserta yang masih kurang.

b. Peserta yang menghadiri pelatihan telah berhasil membuat website pribadi dan membuat deskripsi produknya dengan memanfaatkan SEO dan Google Keyword Planner.

\section{Ucapan Terima Kasih}

Penulis mengucapkan terima kasih atas kesempatan dan dukungan yang diberikan oleh Politeknik Negeri Cilacap (PNC) atas pendanaan yang diberikan melalui hibah skim Program Pengabdian Masyarakat tahun anggaran 2019 dengan nomor kontrak 1177/PL.43/PM.00.01/2019.

\section{Daftar Pustaka}

Harahap, D. A. (2018). Perilaku Belanja Online Di Indonesia: Studi Kasus. JRMSI - Jurnal Riset Manajemen Sains Indonesia, 9(2), 193-213. https://doi.org/10.21009/jrmsi.009.2.02

Jauhari, J. (2014). Upaya Pengembangan Usaha Kecil Dan Menengah (Ukm) Dengan Memanfaatkan E-Commerce. Jurnal Sistem Informasi, 2(1), 159-168. https://doi.org/23554614

LAILY, N. (2016). Analisis Pengaruh Perkembangan Usaha Kecil Menengah (Ukm) Terhadap Pertumbuhan Produk Domestik Regional Bruto (Pdrb). Jurnal Pendidikan Ekonomi (JUPE), 4(3), 1-4.

Saefullah, A., Himawan, \& Arisantoso. (2015). ANALISA PENGARUH PENGGUNAAN SEARCH ENGINE OPTIMIZATION ( SEO ) PADA WEBSITE E-COMMERCE Program Studi Teknik Informatika, Universitas Islam Attahiriyah. Seminar Nasional Sistem Informasi Indonesia, (November), 2-3. Retrieved from http://is.its.ac.id/pubs/oajis/index.php/file/download_file $/ 1546$

Sulistyo. (2010). Pengembangan Usaha Kecil Menengah Dengan Basis Kerakyataan di Kabupaten Malang. Ekonomi Modernisasi, 58-73.

Teguh, C. (2012). Faktor- Faktor Yang Mempengaruhi Minat Beli. JRMB, 7(2), 147-160.

Wahyudi, R., \& Riyanto, A. D. (n.d.). PELATIHAN APLIKASI TEKNIS PENGEMBANGAN ONLINE MARKETING BAGI UKM SE-BALINGMASCAKEB. 1(1), 21-30. 


\section{Afiliasi:}

Annas Setiawan Prabowo, Riyadi Purwanto, Lutfi Syafirullah, Abdul Rohman Supriyono Program Studi D3 Teknik Informatika, Jurusan Teknik Informatika, Politeknik Negeri Cilacap Jalan Dr. Soetomo No. 01, Sidakaya, Cilacap, Jawa Tengah

Devi Taufiq Nurrohman*

Program Studi D3 Teknik Listrik, Jurusan Teknik Elektronika, Politeknik Negeri Cilacap Jalan Dr. Soetomo No. 01, Sidakaya, Cilacap, Jawa Tengah

E-mail : devi.taufiq.n@mail.ugm.ac.id** 